\title{
ARTICLE
}

\section{Human islet function following 20 years of cryogenic biobanking}

\author{
Jocelyn E. Manning Fox ${ }^{1,2}$ - James Lyon ${ }^{1,2} \cdot$ Xiao Qing Dai $^{1,2}$ - Robert C. Wright ${ }^{1,2}$. \\ Julie Hayward $^{1,3}$ - Martijn van de Bunt ${ }^{4,5}$ - Tatsuya Kin ${ }^{1,3}$ - A. M. James Shapiro ${ }^{1,3}$. \\ Mark I. McCarthy ${ }^{4,5,6}$ • Anna L. Gloyn ${ }^{4,5,6}$ • Mark D. Ungrin ${ }^{7}$. Jonathan R. Lakey ${ }^{8}$. \\ Norm M. Kneteman ${ }^{3}$. Garth L. Warnock ${ }^{9}$. Gregory S. Korbutt ${ }^{1,3}$. \\ Raymond V. Rajotte $^{1,10} \cdot$ Patrick E. MacDonald ${ }^{1,2}$
}

Received: 27 November 2014 / Accepted: 7 April 2015 /Published online: 1 May 2015

(C) The Author(s) 2015. This article is published with open access at Springerlink.com

\begin{abstract}
Aims/hypothesis There are potential advantages to the lowtemperature $\left(-196^{\circ} \mathrm{C}\right)$ banking of isolated islets, including the maintenance of viable islets for future research. We therefore assessed the in vitro and in vivo function of islets cryopreserved for nearly 20 years.

Methods Human islets were cryopreserved from 1991 to 2001 and thawed between 2012 and 2014. These were characterised by immunostaining, patch-clamp electrophysiology, insulin secretion, transcriptome analysis and transplantation into a streptozotocin (STZ)-induced mouse model of diabetes.

Results The cryopreservation time was $17.6 \pm 0.4$ years $(n=43)$. The thawed islets stained positive with dithizone, contained insulin-positive and glucagon-positive cells, and displayed levels of apoptosis and transcriptome profiles similar to those of freshly isolated islets, although their insulin content was lower. The cryopreserved beta cells possessed ion channels and exocytotic responses identical to those of freshly isolated beta cells. Cells from a subset of five donors demonstrated similar perifusion insulin secretion profiles pre- and post-cryopreservation. The transplantation of cryopreserved islets into
\end{abstract}

Raymond V. Rajotte

rrajotte@ualberta.ca

Patrick E. MacDonald

pmacdonald@ualberta.ca

1 Alberta Diabetes Institute, University of Alberta, LKS Centre, Edmonton, AB, Canada T6G 2R3

2 Department of Pharmacology, University of Alberta, Edmonton, Canada

3 Department of Surgery, University of Alberta, Edmonton, Canada

4 Oxford Centre for Diabetes, Endocrinology, and Metabolism, University of Oxford, Oxford, UK the diabetic mice improved their glucose tolerance but did not completely normalise their blood glucose levels. Circulating human insulin and insulin-positive grafts were detectable at 10 weeks post-transplantation.

Conclusions/interpretation We have demonstrated the potential for long-term banking of human islets for research, which could enable the use of tissue from a large number of donors with future technologies to gain new insight into diabetes.

Keywords Cryopreservation - Exocytosis · Human · Insulin · Ion channels · Islets - Secretion · Transplantation
Abbreviations
DAB 3,3'-Diaminobenzidine
HRP Horseradish peroxidase
IEQ Islet equivalents
$\mathrm{Kv} \quad$ Voltage-dependent $\mathrm{K}^{+}$
VDCC Voltage-dependent $\mathrm{Ca}^{2+}$ channel

5 Wellcome Trust Centre for Human Genetics, University of Oxford, Oxford, UK

6 Oxford NIHR Biomedical Research Centre, Churchill Hospital, Oxford, UK

7 Faculty of Veterinary Medicine, University of Calgary, Calgary, Canada

8 Departments of Surgery and Biomedical Engineering, University of California, Irvine, USA

9 Department of Surgery, University of British Columbia, Vancouver, Canada

10 Department of Surgery, Surgical Medical Research Institute, HMRC, University of Alberta, Edmonton, AB, Canada T6G 2S2 


\section{Introduction}

The ability to preserve human islets for an extended period of time has several benefits. These may include increasing the practicality of islet transplantation for type 1 diabetes by improving the prospects for pre-transplant testing, simultaneous multiple donor transplants and simplified logistics. However, human islets are increasingly being recognised as a valuable research resource [1], and concerns have been raised about the future of access to human research islets [2]. Biobanking is one way to address this and to facilitate the progress of research into the mechanisms underlying diabetes. However, the successful storage of functional islets has not been achieved beyond 2 years - far too short a time for successful long-term biobanking.

Culturing islets extends their viable lifespan to a certain degree, but long-term maintenance of the phenotype has proved problematic $[3,4]$. Schmied et al have reported the maintenance of endocrine cells to be limited to 60 days, with hormone secretion lost by day 28 [5], although Fraga et al observed glucose-stimulated insulin secretion following 2 months of culture [6]. The cryopreservation of islets has been considered to be a potential tool since the first demonstrations of the reversal of hyperglycaemia by frozen-thawed islets in rats used as a model of streptozotocin (STZ)-induced diabetes $[7,8]$. Cryopreservation was initially undertaken with rodent and canine islets, and the cryopreservation of human islets was first reported in 1980 [9]. Using a protocol we had developed by 1989 [10, 11], we obtained reasonable results using islets cryopreserved for an average of 44 days, in which the insulin secretory responses were $79 \%$ of the pre-freezing levels [12]. The transplantation of a mixture of fresh and cryopreserved islets into patients with type 1 diabetes receiving kidney transplants demonstrated long-term graft function, with one patient becoming independent of insulin for 2.5 years $[13,14]$.

In the past 10 years, new cryopreservation protocols have been developed in an attempt to improve islet viability after thawing. These include pre- and post-culture with astragalosides, Sertoli cells, ductal epithelia, antioxidants and P38 MAP kinase (MAPK) inhibition [15-19]. Numerous cryoprotectants, including silk protein, DMSO, hydroxyethyl starch, glycerol and synthetic glycoprotein, have been investigated [20-23]. More recently, there has been a report of an increased duration of cryopreservation (3 months) and an assessment of post-thawing status including gene expression profiling, viability, insulin secretion and in vivo engraftment [24]. In addition, Misler et al have investigated the electrophysiological and secretory responses of islets following cryopreservation for up to 2 years [25].

Although the cryopreservation of human islets would be beneficial in enabling their future use, a true long-term banking of functional islets has not been reported. The University of Alberta is exceptional in terms of its large biobank of cryopreserved human islets [26]. Despite their success in clinical trials $[13,27]$, these frozen islets have, however, been deemed to be unsuitable for transplantation using the Edmonton protocol [28] owing to the presence of FBS. As such, preparations for which the donors had given research consent were designated as research islets. Here we assess the function of human islets obtained from this facility following cryopreservation for up to 21 years and demonstrate the potential for this approach to provide a source of high-quality, viable research tissue.

\section{Methods}

Human islets We thawed and examined cryopreserved islet preparations from 43 human donors. These had been cryopreserved using the method developed by Rajotte et al [11] with DMSO as a cryoprotectant and had been stored under liquid-phase $\mathrm{N}_{2}$ for $17.6 \pm 0.4$ years. The mean age of the donors was $40.9 \pm 2.0$ years, with $47 \%$ male vs $53 \%$ female donors. Freshly isolated islets were obtained from the Alberta Diabetes Institute IsletCore and the Clinical Islet Laboratory at the University of Alberta. The mean age of the donors of these was $60.5 \pm 3.0$ years, with $56 \%$ male vs $43 \%$ female donors. All the studies were approved by the Human Research Ethics Board at the University of Alberta.

Human islet culture Cryopreserved islet preparations were thawed by rapid $\left(150^{\circ} \mathrm{C} / \mathrm{min}\right)$ warming to $4^{\circ} \mathrm{C}$ followed by the removal of DMSO with a sucrose gradient and serial dilution of cryoprotectant [11]. The islets were subsequently cultured overnight in CMRL 1066 (Corning, Tewksbury, MA, USA) supplemented with $0.5 \%$ BSA (Equitech-Bio, Kerrville, TX, USA), 1\% Insulin-Transferrin-Selenium (Corning), $100 \mathrm{U} / \mathrm{mL}$ penicillin/streptomycin (Life Technologies, Burlington, ON, Canada) and L-glutamine (Sigma-Aldrich, Oakville, ON, Canada). Both the cryopreserved and the freshly isolated islets were cultured for an additional $24 \mathrm{~h}$ in lowglucose $(1 \mathrm{~g} / \mathrm{L})$ DMEM supplemented with $10 \%$ FBS and $100 \mathrm{U} / \mathrm{mL}$ penicillin/streptomycin.

Transcriptome analysis Thawed islets ( $n=32$ donors) or freshly isolated islets ( $n=18$ donors) were hand-picked and RNA was extracted using Trizol reagent (Life Technologies). RNA sequencing was performed on an Illumina HiSeq 2000 (Illumina, San Diego, CA, USA) with 100 bp paired-end sequencing. Libraries were prepared using the NEBNext Ultra Directional RNA Library Prep Kit for Illumina (New England BioLabs, Hitchin, UK) with custom 8 bp indexes [29]. The TruSeq PE Cluster Kit v3 (Illumina) was used for cluster generation and the TruSeq SBS Kit v3 (Illumina) for sequencing. 
Sequenced reads were mapped to the human genome (GRCh37) with Tophat v2.0.12 (www.ccb.jhu.edu/software/ tophat/index.shtml) [30] using Gencode v18 (www. gencodegenes.org) as the transcriptome reference. Expression was quantified using Cuffquant and Cuffnorm (http://cole-trapnell-lab.github.io/cufflinks/) [30] on default settings.

Immunohistochemistry and TUNEL staining Islets and islet grafts were fixed in Z-fix (Anatech, Battle Creek, MI, USA), embedded in paraffin and sliced into $5 \mu \mathrm{m}$ sections. Immunostaining for insulin (Santa Cruz Biotechnology, Dallas TX, USA; or DAKO Canada, Burlington, ON, Canada) and glucagon (EMD Millipore, Billerica, MA, USA) was performed as previously described [31]. Apoptosis was assessed by in situ TUNEL (Roche Diagnostics, Laval, QC, Canada) according to the manufacturer's instructions. Slides were coverslipped with prolong gold antifade with DAPI, visualised with an Axioscope II with AxioCamMRC and analysed using Axiovision 4.6 (Carl Zeiss, Gottingen, Germany).

Electrophysiology The islets were dispersed by shaking in dissociation buffer (Life Technologies) and plated in $35 \mathrm{~mm}$ dishes. The standard whole-cell technique was used with the sine+DC lock-in function of an EPC10 amplifier and Patchmaster software (HEKA Electronik, Lambrecht/Pfalz, Germany). Experiments were performed at $32-35^{\circ} \mathrm{C}$. To measure the voltage-dependent $\mathrm{K}^{+}(\mathrm{Kv})$ currents, an intracellular solution was used containing (in mmol/l): $140 \mathrm{KCl}, 1 \mathrm{CaCl}_{2}, 1$ $\mathrm{MgCl}_{2}, 10$ HEPES, 10 EGTA and 3 ATP-Mg (pH 7.3 with $\mathrm{KOH}$ ). The bath solution contained (in mmol/l): $135 \mathrm{NaCl}$, $5.4 \mathrm{KCl}, 1 \mathrm{CaCl}_{2}, 1.2 \mathrm{MgCl}_{2}, 10$ HEPES and 5 glucose $(\mathrm{pH}$ 7.3 with $\mathrm{NaOH}$ ). To measure the capacitance, a bath solution was used that contained (in mmol/l): $118 \mathrm{NaCl}, 20$ tetraethylammonium chloride, $5.6 \mathrm{KCl}, 1.2 \mathrm{MgCl}_{2} \cdot 6 \mathrm{H}_{2} \mathrm{O}$, $2.6 \mathrm{CaCl}_{2}, 1$ or 10 glucose and 5 HEPES (pH 7.4 with $\mathrm{NaOH}$ ). The pipette solution for capacitance measurement contained (in mmol/l): 125 Cs-glutamate, $10 \mathrm{CsCl}, 10 \mathrm{NaCl}$, $1 \mathrm{MgCl}_{2} \cdot 6 \mathrm{H}_{2} \mathrm{O}, 0.05$ EGTA, 5 HEPES, $0.1 \mathrm{cAMP}$ and 3 MgATP (pH 7.15 with $\mathrm{CsOH}$ ). The patch pipettes, pulled from borosilicate glass and coated with Sylgard (World Precision instruments, Sarasota, FL, USA), had resistances of 3-4 M $\Omega$ when filled with pipette solution. The whole-cell $\mathrm{Kv}$ current and capacitance responses were normalised to the initial cell size and expressed as $\mathrm{pA} / \mathrm{pF}$ and $\mathrm{fF} / \mathrm{pF}$, respectively. The beta cells were positively identified after the experiment by insulin immunostaining.

Insulin secretion Static insulin secretion measurements were performed at $37^{\circ} \mathrm{C}$ in $\mathrm{KRB}$ (in mmol/l: $115 \mathrm{NaCl}, 5 \mathrm{KCl}, 24$ $\mathrm{NaHCO}_{3}, 2.5 \mathrm{CaCl}_{2}, 1 \mathrm{MgCl}_{2}, 10$ HEPES and $0.1 \% \mathrm{BSA} ; \mathrm{pH}$ 7.4). Twenty islets per group were pre-incubated for $2 \mathrm{~h}$ in
$1 \mathrm{mmol} / \mathrm{l}$ glucose KRB. These were subsequently incubated for $1 \mathrm{~h}$ in KRB with $1 \mathrm{mmol} / \mathrm{l}$ glucose, followed by $1 \mathrm{~h}$ with $16.7 \mathrm{mmol} / 1$ glucose and then $1 \mathrm{~h}$ with $16.7 \mathrm{mmol} / 1$ glucose plus $20 \mathrm{mmol} / 1 \mathrm{KCl}$. The islets were extracted with acid/ethanol to determine their insulin content. The samples were stored at $-20^{\circ} \mathrm{C}$ and assayed for insulin using an electrochemiluminescence assay (Meso Scale Discovery, Rockville, MD, USA).

Insulin secretion was measured pre- and postcryopreservation in five donors by perifusion assay. Precryopreserved islets were perfused with Hanks' Balanced Salt Solution (containing 2.8 or $28 \mathrm{mmol} / \mathrm{l}$ glucose), and samples were collected and assayed for insulin using radioimmunoassay. Post-thaw insulin perifusions were performed using a PERI-4.2 perifusion machine (Biorep Technologies, Miami, FL, USA). Twenty islets per chamber were perfused with $\mathrm{KRB}$ (containing 2.8 or $28 \mathrm{mmol} / \mathrm{l}$ glucose) at a flow rate of $250 \mu \mathrm{l} / \mathrm{min}$ with samples collected at $2 \mathrm{~min}$ intervals.

Islet transplantation Male B6.129S7-Ragl $1^{\mathrm{tm} 1 \mathrm{Mom} / \mathrm{J}}(\mathrm{B} 6 /$ $\mathrm{Rag}^{-(-)}$mice (Jackson Laboratory, Bar Harbor, ME, USA) were rendered diabetic by the intraperitoneal injection of streptozotocin (STZ; $185 \mathrm{mg} / \mathrm{kg}$ ). Three days after the induction of diabetes, islets thawed after cryopreservation $(2,000$ or 4,000 islet equivalents [IEQ]) or freshly isolated islets $(3,000$ IEQ) were transplanted under the kidney capsules of the mice [32]. Their body weight and blood glucose levels were monitored over 10 weeks. Blood glucose and plasma insulin (Meso Scale Discovery) were both measured in response to an oral glucose load ( $3 \mathrm{mg} / \mathrm{g}$ body weight) pre- and post-nephrectomy, which occurred at week 10 . The islet graft was extracted in acid-ethanol to determine the insulin content or embedded and sectioned for immunohistochemistry. All murine experiments were approved by the Animal Care and Use Committee at the University of Alberta.

Data analysis Data were analysed using FitMaster (HEKA Electronik) and Origin 9.1 (OriginLab, Northampton, MA, USA) and compared using multiple ANOVA and the Student's $t$ test. Data are expressed as mean $\pm \mathrm{SE}$, and $p<0.05$ was considered significant.

\section{Results}

Human islets following long-term cryopreservation and thawing Human islet preparations $(n=43$, frozen for $17.6 \pm$ 0.4 years) were rapidly thawed using the method described by Rajotte et al [11] to limit osmotic damage. The cells were immediately stained with dithizone (Fig. 1a). Estimates of islet purity pre- and post-cryopreservation were positively correlated (slope $=0.84, r^{2}=0.73, p<0.001$; Fig. 1b), and cryopreservation did not significantly decrease the purity $(51.2 \pm 4.4$ vs 
$47.2 \pm 4.1 \%, n=41)$. Immunofluorescence staining revealed the expression of both insulin-positive beta cells and glucagon-positive alpha cells (Fig. 1c), which appeared to be similar in their distribution to previous reports [33]. Apoptosis, assessed by TUNEL, did not differ between freshly isolated $(9.4 \pm 1.2 \%, n=4$ donors) and cryopreserved islets $(8.9 \pm 1.8 \%, n=5$ donors; Fig. $1 \mathrm{~d}$, e) and was similar to values previously reported [34-37].

Cryopreserved beta cells retain ion channel function and exocytotic responsiveness A critical component of beta cell function is the electrical activity mediated by the ion channels, leading to $\mathrm{Ca}^{2+}$ influx and the exocytosis of insulin-containing granules [38, 39]. Whole-cell patchclamp was used to assess the Kv current, a key regulator of action potentials and insulin secretion [40, 41]. The
$\mathrm{Kv}$ currents from cryopreserved ( $n=15$ donors, 45 cells) and freshly isolated ( $n=3$ donors, 15 cells) beta cells identified by positive insulin immunostaining were simi$\operatorname{lar}(138.6 \pm 11.7$ vs $130.3 \pm 11.3 \mathrm{pA} / \mathrm{pF}$; Fig. 2a, b).

Voltage-dependent $\mathrm{Ca}^{2+}$ channels (VDCCs) underlie the influx of $\mathrm{Ca}^{2+}$ on glucose-stimulated membrane depolarisation to trigger the release of insulin granules [41]. VDCC currents exhibited similar activity in cryopreserved beta cells $(-0.68 \pm 0.09 \mathrm{pC} / \mathrm{pF}, n=8$ donors, 31 cells $)$ and freshly isolated beta cells $(-0.50 \pm 0.07 \mathrm{pC} / \mathrm{pF}, n=6$ donors, 24 cells; Fig. 2c, d). Although the beta cells from the cryopreserved islets tended to show a larger $\mathrm{Ca}^{2+}$ entry in response to depolarisation, this was not statistically significant.

The fusion of insulin granules with the cell membrane can be measured as an increase in cell capacitance in response to a train of depolarisations [42]. The magnitude of this response is
Fig. 1 Human islets following long-term cryopreservation. (a) Islets were stained with dithizone immediately following isolation or on thawing following longterm cryopreservation. Scale bar, $1 \mathrm{~mm}$. (b) Correlation of islet purity estimates at isolation (Prefreeze) and after thawing (Postthaw). (c) Representative image of a long-term cryopreserved islet, immunostained for insulin (green) and glucagon (red), with nuclei stained with DAPI (blue). Scale bar, $100 \mu \mathrm{m}$. (d)

Representative image of a freshly isolated and a cryopreserved islet stained for insulin (red), TUNEL (green) and DAPI (blue). Scale bar, $100 \mu \mathrm{m}$. (e) Percentage of apoptotic (TUNEL-positive) cells within freshly isolated islets from four donors (grey circles) and cryopreserved islets from five donors after thawing (black circles). Each circle represents a separate image set $(17,185$ cells $)$ a
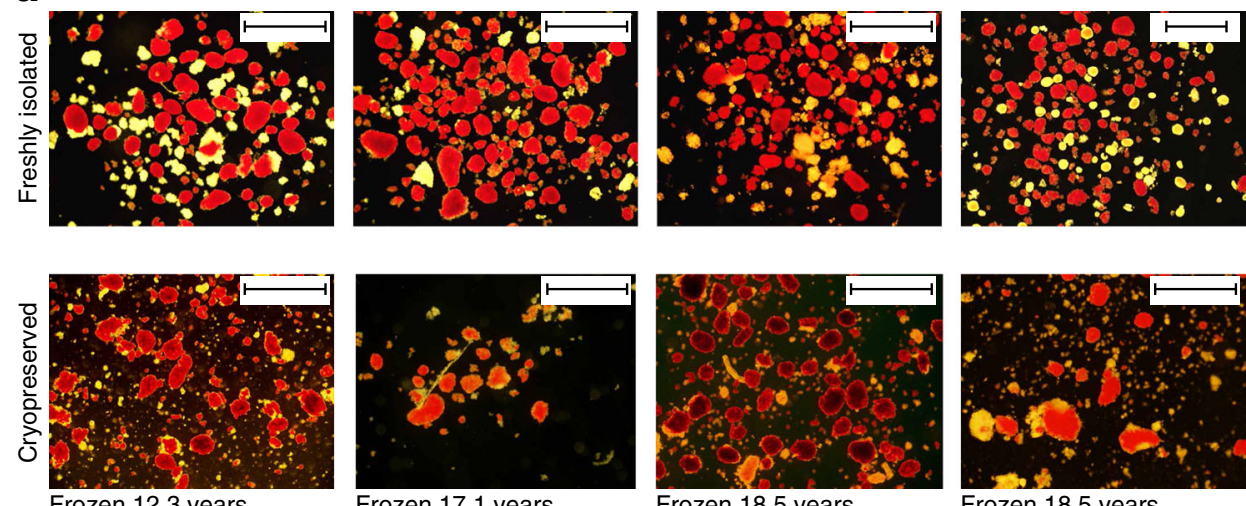

Frozen 17.1 years

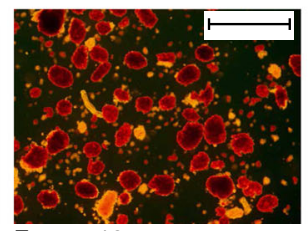

Frozen 18.5 years

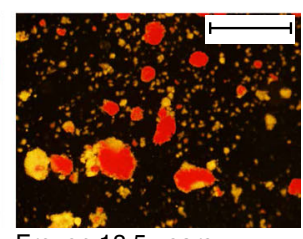

Frozen 18.5 years

b

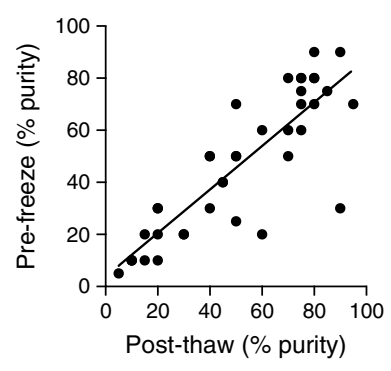

d

\section{Freshly isolated}

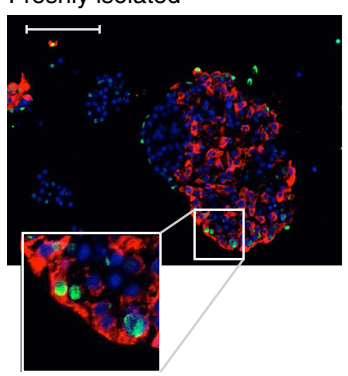

Cryopreserved

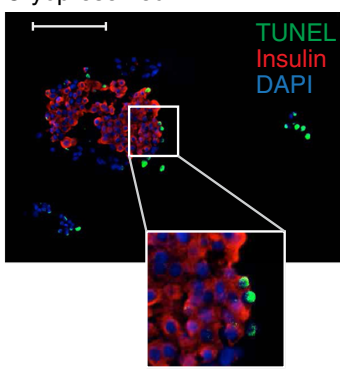

C

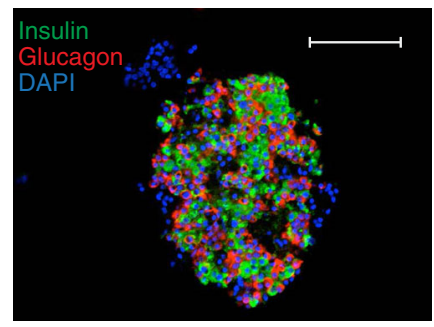

Frozen 18.5 years e

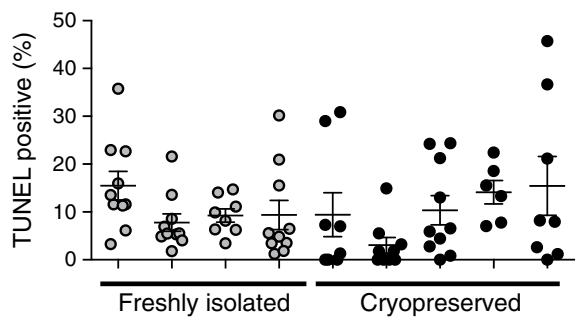


a $0 \mathrm{mV}$
$-70 \mathrm{mV}$

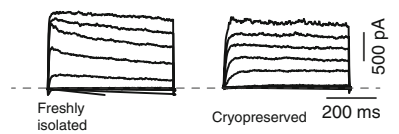

C

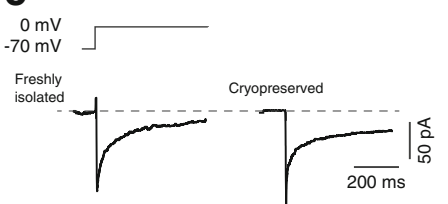

e

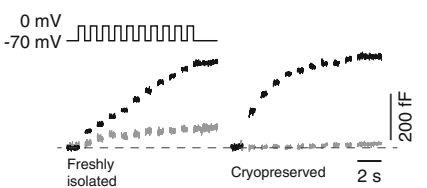

b

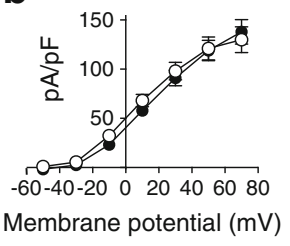

d

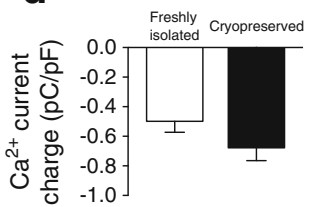

f

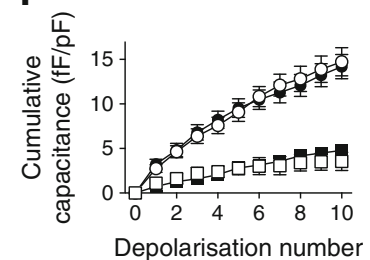

Fig. 2 Single cell function is maintained in long-term cryopreserved human beta cells. (a, b) Representative Kv currents and current-voltage relationships from freshly isolated (white circles) and long-term cryopreserved (black circles) human beta cells. (c, d) Representative VDCCs and $\mathrm{Ca}^{2+}$-charge entry during depolarisation in freshly isolated (white bar) and long-term cryopreserved (black bar) human beta cells. (e, f) Representative exocytotic responses, shown as increases in membrane capacitance (i.e. surface area) in response to a series of membrane depolarisations, and summarised data from freshly isolated (white symbols) and long-term cryopreserved (black symbols) human beta cells in response to $1 \mathrm{mmol} / \mathrm{l}$ (squares) and $10 \mathrm{mmol} / \mathrm{l}$ (circles) glucose. In all experiments, the beta cells were positively identified by immunostaining for insulin

sensitive to glucose level in healthy beta cells [43], probably reflecting a metabolism-driven increase in insulin granule trafficking or priming. The cryopreserved beta cells had intact exocytotic responses and retained their sensitivity to glucose $(5.0 \pm 0.6 \mathrm{fF} / \mathrm{pF}$ at $1 \mathrm{mmol} / 1$ glucose vs $15.0 \pm 1.4 \mathrm{fF} / \mathrm{pF}$ at $10 \mathrm{mmol} / 1$ glucose, $n=9$ donors, $46-70$ cells), which was similar to that seen in healthy, freshly isolated beta cells $(4.1 \pm$ $0.9 \mathrm{fF} / \mathrm{pF}$ at $1 \mathrm{mmol} / \mathrm{lglucose} \mathrm{vs} 17.0 \pm 2.2 \mathrm{fF} / \mathrm{pF}$ at $10 \mathrm{mmol} / \mathrm{l}$ glucose, $n=6$ donors, 20-26 cells; Fig. 2e, f).

\section{Cryopreserved human islets exhibit glucose-stimulated} insulin secretion Our electrophysiological studies indicated that the ion channels and exocytotic machinery necessary to elicit insulin granule fusion remained intact following cryopreservation. We were able to directly compare the secretory profile of the islets from five donors before cryopreservation (Fig. 3a) and then after thawing almost 20 years later (Fig. 3b). Glucose-stimulated $(28 \mathrm{mmol} / \mathrm{l})$ secretion was remarkably similar in magnitude both pre- and post-cryopreservation, with a modest difference in the profile that was likely to be
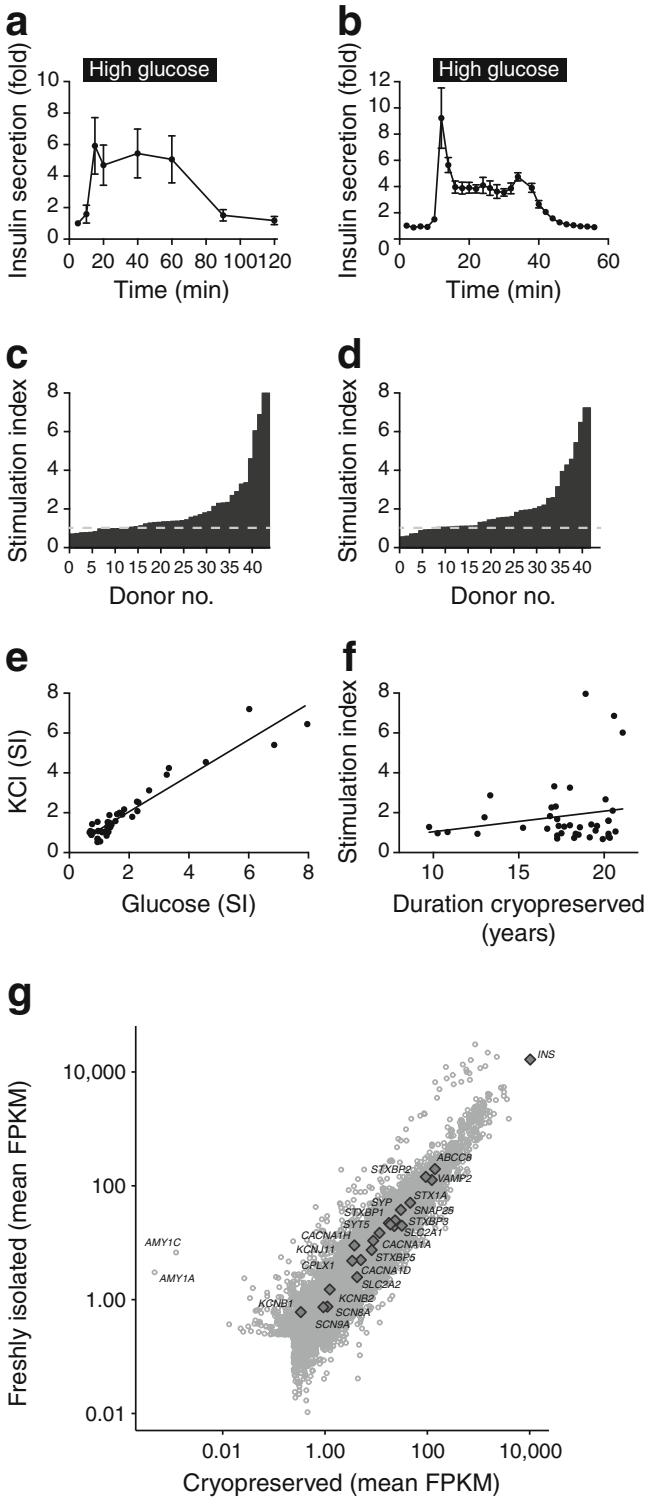

Fig. 3 Function of intact cryopreserved human islets in vitro. (a, b) Insulin secretion measured by perifusion in response to $28 \mathrm{mmol} / \mathrm{lglu}-$ cose (high glucose) from islets following isolation (a) and then from the same preparations after thawing approximately 20 years later (b). (c, d) Static insulin secretory responses of long-term cryopreserved islets to $16.7 \mathrm{mmol} / 1$ glucose alone (c) or with $20 \mathrm{mmol} / 1 \mathrm{KCl}(\mathbf{d})$. (e, f) The secretory responses to $\mathrm{KCl}$ and glucose were positively correlated (e), but secretory competence did not correlate with the duration of cryopreservation (f). (g) Transcriptome analysis demonstrated a high degree of correlation of transcript expression between cryopreserved and freshly isolated islets (Spearman's $\rho=0.94$ ). The expression level of several beta cell function genes is indicated. FPKM, fragments per kilobase of exon per million fragments mapped; SI, stimulation index

attributable to improved methodology or increased sampling frequency.

The secretion of insulin from the islets was measured following static incubation with $1 \mathrm{mmol} / \mathrm{l}$ glucose, $16.7 \mathrm{mmol} /$ 1 glucose or $16.7 \mathrm{mmol} / \mathrm{l}$ glucose plus $20 \mathrm{mmol} / \mathrm{l} \mathrm{KCl}$. Glucose 
and $\mathrm{KCl}$ stimulated insulin secretion with stimulation indices of $1.90 \pm 0.24$ and $1.96 \pm 0.24$, respectively ( $n=41-43$ donors). The stimulation of insulin secretion in response to glucose $(n=$ $43)$ and $\mathrm{KCl}(n=41)$ reached statistical significance (at $p<0.05$ ) for $37.2 \%$ and $41.5 \%$ of donors, respectively (Fig. 3c, d). The total insulin content of the cryopreserved islets (11.1 $\pm 1.4 \mathrm{ng} /$ islet, $n=43)$ was significantly lower than what we can observe in freshly isolated islets today (24.3 \pm $2.3 \mathrm{ng} /$ islet, $n=56, p<0.001$ ). However, due to a lack of historical data on the insulin content, we do not know whether this was reduced at the time of isolation or by the cryopreservation process per se.

Although there was a significant linear correlation $\left(r^{2}=\right.$ $0.91, p<0.001)$ between glucose sensitivity and $\mathrm{KCl}$ sensitivity (Fig. 3e), the duration of cryopreservation did not correlate $\left(r^{2}=0.03\right)$ with the glucose-stimulated insulin secretion (Fig. 3f). This preserved functional capacity is consistent with our assessment of transcript expression profiles by RNA sequencing (Fig. 3g) and our demonstration of a similar expression of the exocytotic and ion channel genes. There is strong correlation (Spearman's $\rho=0.94$ ) between the transcriptomes of the cryopreserved and the fresh islets. The two outliers observed in Fig. 3g are $A M Y 1 A$ and $A M Y 1 C$, suggesting differences in islet purity (although this is likely to be due to the hand-picking of cryopreserved islets prior to the transcriptome analysis).

\section{Partial functioning of cryopreserved islets transplanted} into diabetic mice To ascertain the extent to which longterm cryopreserved islets can function in an in vivo model, we transplanted 2,000-4,000 IEQ from five donors (cryopreserved for $16.6 \pm 1.1$ years, stimulation index $1.9 \pm 0.4$, four to five recipient animals each) under the kidney capsule of STZinduced diabetic B6/ $\mathrm{Rag}^{-/-}$mice. Transplantation significantly decreased blood glucose levels $(n=5$ donors, 23 animals, $p<0.05$ ) but did not restore normoglycaemia (Fig. 4a). The success of engraftment varied between donors, with only one group achieving glucose levels similar to those of freshly isolated islets ( $n=5$ donors, 11 mice), although this occurred after a prolonged delay (Fig. 4b). The success of the engraftment did not correlate with the stimulation index but did correlate significantly $\left(r^{2}=0.84, p<0.05\right)$ with the insulin content of the donor islets (Fig. 4c). In all cases, however, the transplanted cryopreserved islets were sufficient to maintain the animal's body weight (Fig. 4d). Human insulin was detected in most recipient mice following fasting and was significantly $\left(r^{2}=\right.$ $0.73, p<0.001)$ correlated with improvements in fasting glucose levels (Fig. 4e).

In mice receiving grafts of cryopreserved islets, OGTTs were performed at week 10 and again 1 week following graft removal. Although the animals were hyperglycaemic, their blood glucose excursions were significantly improved by the graft $(n=23, p<0.001$; Fig. $4 \mathrm{f})$, and graft removal increased
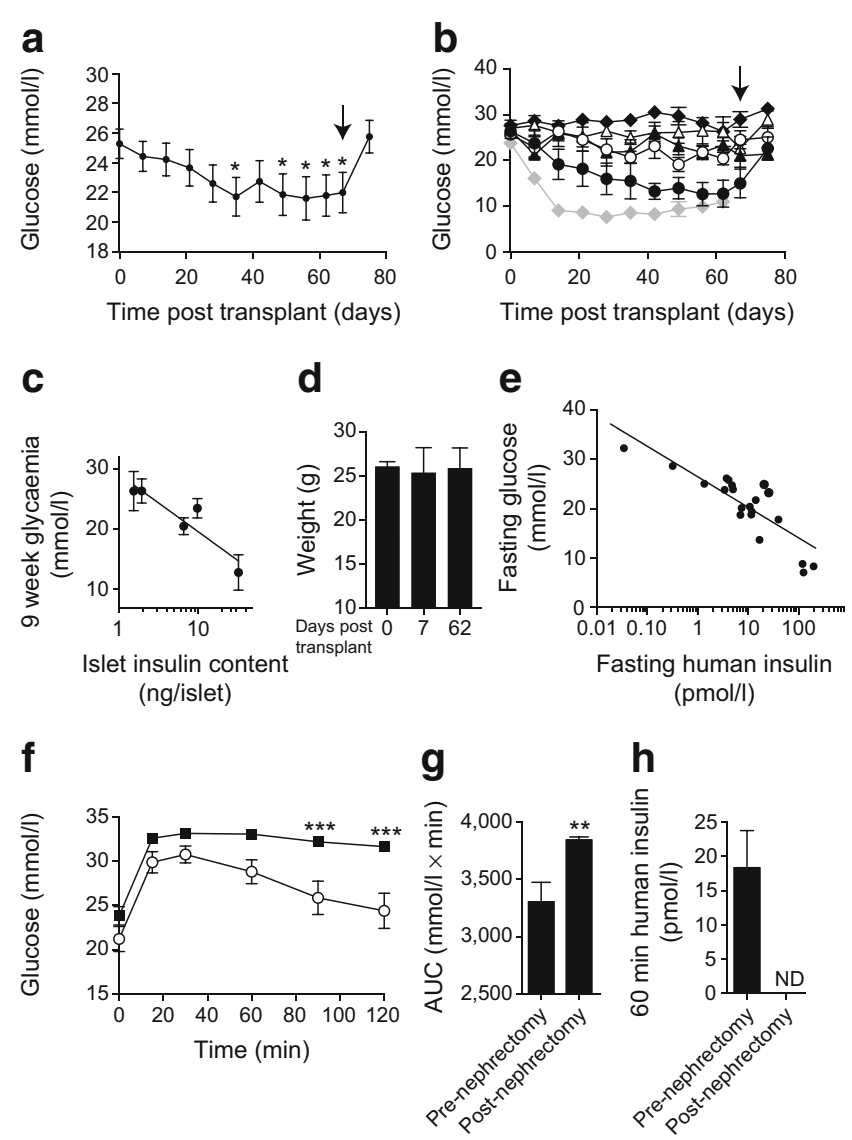

Fig. 4 Long-term cryopreserved human islets are partially functional in vivo. (a) Sub-capsular grafts of cryopreserved human islets $(2,000$ 4,000 IEQ) from five separate donors produced a marginal improvement in blood glucose level in STZ-diabetic B6/ $\mathrm{Rag}^{-1-}$ mice, which was reversed by removal of the graft-bearing kidney (arrow). (b) Glycaemic responses to grafts from each of five donors are shown, compared with the effect of freshly isolated human islets (3,000 IEQ; grey line). The grafts were removed at the time indicated by the arrow. (c) The success of reversal of diabetes at 9 weeks correlates with the insulin content of the cryopreserved islet preparations. (d) Body weight was maintained in the STZ-diabetic B6/Rag ${ }^{-/-}$mice following the transplantation of cryopreserved human islets. (e) Human insulin was detectable in fasted STZdiabetic B6/ $\mathrm{Rag}^{-/-}$recipient mice, and levels correlated negatively with fasting blood glucose levels. (f-h) Long-term cryopreserved islets improved intraperitoneal glucose tolerance (white circles) and the AUC of the glucose response in STZ-diabetic B6/ $\mathrm{Rag}^{-/-}$mice, as well as producing human insulin (h). After removal of the engrafted kidney (black squares), the glucose excursion was elevated and circulating human insulin was not detectable (ND). ${ }^{*} p<0.5,{ }^{* *} p<0.01$ and ${ }^{* * *} p<0.001$ compared with time $=0$ or the pre-nephrectomy control

the area under the glucose curve $(n=23, p<0.01)$ (Fig. 4g). Since the maximum value of the capillary glucose meter is $33.3 \mathrm{mmol} / \mathrm{l}$, the true blood glucose values postnephrectomy are likely to be higher than reported. Circulating human insulin at $60 \mathrm{~min}$ following glucose challenge, which was detectable in recipient mice pre-nephrectomy, was absent following graft removal (Fig. 4h).

Anti-insulin-horseradish peroxidase (HRP)/3,3'-diaminobenzidine (DAB) (Fig. 5a, b) and immunofluorescence (Fig. 5c) 
Fig. 5 Human insulin is detectable in grafts of long-term cryopreserved human islets after 10 weeks. (a, b) Anti-insulin $\mathrm{HRP} / \mathrm{DAB}$ staining of renal sub-capsular grafts of long-term cryopreserved human islets. (c) Insulin (red) and glucagon (green) immunofluorescence and DAPI staining (blue) in a section of a graft of cryopreserved islets removed after 10 weeks. (d-h) Insulin immunostaining (red) and DAPI staining (blue) of grafts of freshly isolated islets from three separate donors (d) and long-term cryopreserved islets from four separate donors $(\mathbf{e}-\mathbf{h})$. The cryopreserved islets shown were from donors that reduced the blood glucose level in recipient mice to $12.4(\mathbf{e}), 20.4(\mathbf{f}), 26.3(\mathrm{~g})$ and 23.4 (h) $\mathrm{mmol} / \mathrm{l}$. Scale bar, $100 \mu \mathrm{m}(\mathbf{a})$ or $200 \mu \mathrm{m}(\mathbf{b}-\mathbf{e})$

\section{a}

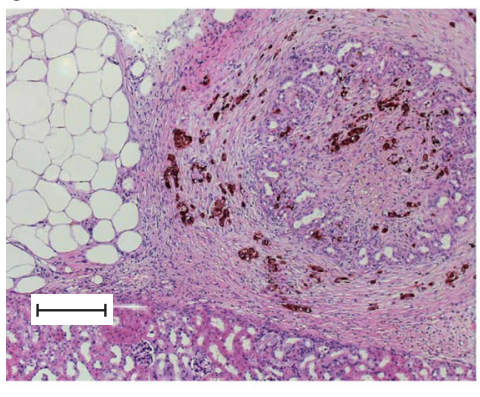

b

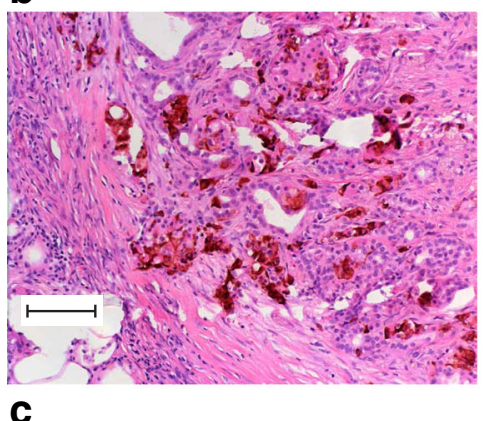

C

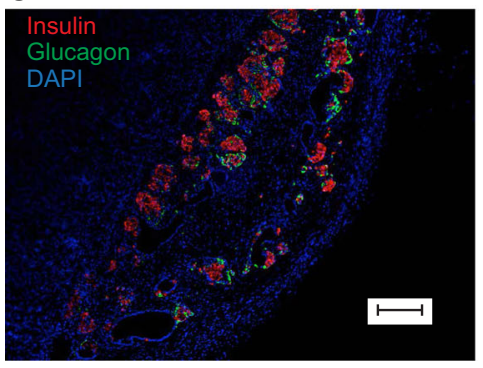

d
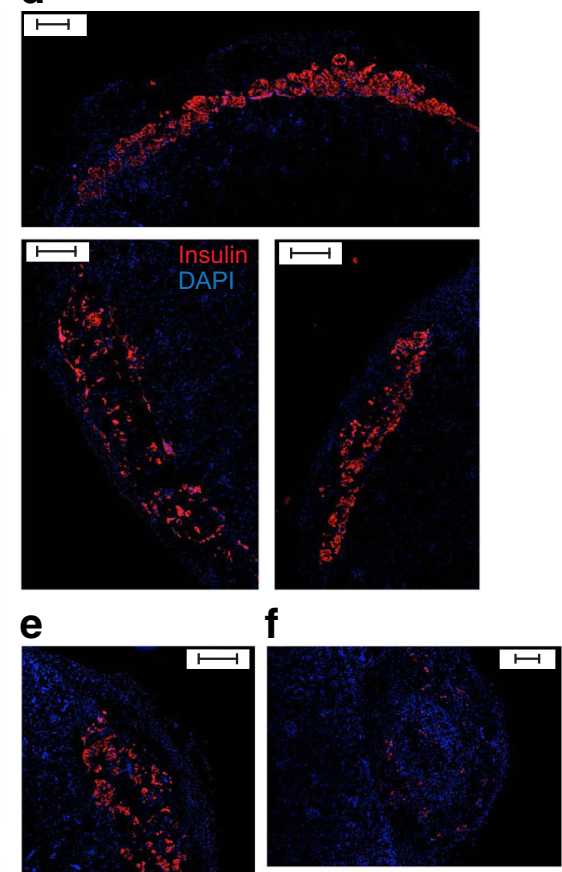

h

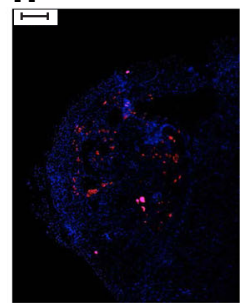

revealed the retention of human insulin in cryopreserved islet grafts from four out of five donors after 10 weeks. However, although grafts of freshly isolated islets showed strong insulinpositive staining (Fig. 5d), the insulin staining of cryopreserved islet grafts appeared to be weaker (Fig. 5e-h), consistent with the lower islet insulin content observed above. The total insulin content of the grafts of cryopreserved islets was $399.1 \pm$ $119.4 \mathrm{ng} / \mathrm{graft}$ ( $n=12$ grafts, five donors). The level of apoptosis did not differ between the fresh $(4.3 \pm 1.6 \%, n=10)$ and the cryopreserved $(5.4 \pm 2.0 \%, n=6)$ grafts.

\section{Discussion}

This is the first report of human islet function following extended cryopreservation in a large cohort of donors and suggests that the potential storage duration of functional islets can be increased by an order of magnitude. We have assessed various steps in the stimulus-secretion coupling pathway and provide data indicating that long-term cryopreservation provides a source of human islet material for research that retains many physiologically relevant properties. Access to human research islets remains a limiting factor in many scientific studies [2], and the inherent difficulties of distribution and culture time only add further to the value of any human islet tissue obtained. Biobanking has the potential to overcome many of these issues, and the successful retention of physiological function in frozen-thawed islets is desirable.

When assessing beta cell function, several critical components of stimulus-secretion coupling must be considered. These include ion channel activity, which underlies the electrical signal produced in response to glucose stimulation, $\mathrm{Ca}^{2+}$ influx and the exocytotic machinery responsible for the release of insulin granules [38, 39]. Ultimately, glucosestimulated insulin secretion and the ability to restore physiological glucose homeostasis are of key significance.

Our patch-clamp studies revealed that key ion conductances underlying beta cell excitability remain identical to those observed in freshly isolated beta cells following up to 21 years of cryopreservation. In addition, measurement of the exocytotic capacity and glucose sensitivity of single beta cells demonstrates responses that are indistinguishable from those of freshly isolated beta cells. These findings expand on those of Misler et al, who previously measured electrical activity 
and exocytosis in human islets cryopreserved for a much shorter period in a small cohort of donors [25]. Our data indicate that cryopreserved human islets can serve as an appropriate physiological model in at least some cellular mechanistic studies.

While these underlying cellular processes remain intact, in vitro insulin secretion and islet insulin content appear to be more variable in the cryopreserved islets. The mean glucose stimulation index of $1.90 \pm 0.24(n=43)$ is low compared with the values we typically observe today with freshly isolated human islets $(9.53 \pm 0.92, n=56$; range $1.04-33.83)$. A reduction in insulin secretory capacity has frequently been reported following the cryopreservation of human islets $[16,22$, $25,44,45]$. However, given the limited historical data available to us, we could only make a direct pre- and postcryopreservation comparison for five donors (Fig. 3a, b). As the secretory profiles for these donors were similar before and after freezing, it is difficult to conclude that cryopreservation per se caused a reduced secretory response in our study. Notably, the return to baseline secretion in the perifusion, which is difficult to achieve in rat islets cryopreserved using other protocols [10], suggests that these islets were viable. Finally, the transcriptome profiles of fresh and cryopreserved islets were similar, including the expression of genes that correlate with the measurements made here: for insulin (INS), $\mathrm{Kv}$ currents (i.e. $K C N B 1$ and $K C N B 2$ ), $\mathrm{Ca}^{2+}$ currents (i.e. $C A C N$ $A 1 A, C A C N A 1 H$ and $C A C N A 1 D$ ) and exocytosis (i.e. VAMP2, STX1A, SNAP25, CPLX1 and SYP).

Our transplantation of cryopreserved islets into STZinduced diabetic mice revealed that in vivo function varies and correlates with islet insulin content. As above, however, because we do not have data on the pre-freezing insulin content, we cannot say whether cryopreservation itself reduces the insulin content or whether this was already lower prior to freezing. Overall, the cryopreserved islets performed relatively poorly in their ability to normalise blood glucose level in vivo. The maintenance of the recipients' body weights and the presence of circulating human insulin, which correlated inversely with blood glucose level, indicate, however, that the cryopreserved islets maintained some function in vivo. This is supported by the OGTTs, which showed that the grafts were limiting the blood glucose excursion. Most grafts retained endocrine cell expression for the full 10 weeks. Indeed, graftremoving nephrectomy completely abolished the plasma insulin and resulted in severe glucose intolerance. Thus, we conclude that the cryopreserved human islet grafts retained at least some function in vivo, but the reversal of diabetes was limited by the reduced insulin content of these islets.

In summary, we have demonstrated that long-term cryopreserved islets may be suitable for cellular studies of the mechanisms underlying stimulus-secretion coupling in beta cells, although further work is required to determine the potential effects of long-term cryopreservation on insulin content that may limit their in vivo efficacy. The progress of science and technology is rapid. These human islets were isolated and cryopreserved in an era when many of today's modern techniques were undeveloped or prohibitive in terms of cost. In less than two decades, the research potential of this tissue has dramatically increased. The ongoing banking of human islets is therefore important in order to preserve tissue for the evaluation of currently unidentified targets and pathways using advanced technologies, which will facilitate future research.

Acknowledgements The authors thank the Human Organ Procurement and Exchange (HOPE) programme in Alberta and the Trillium Gift of Life Network (TGLN) in Ontario for their efforts in obtaining human pancreas for research. We also thank A. Muir (University of Alberta, Edmonton, Canada) for his dedication to the maintenance of our cryogenic biobank over more than 20 years, and A. Barrett (University of Oxford, Oxford, UK) for her contribution to the preparation of samples for RNA sequencing analysis.

Funding Funding came from the Alberta Diabetes Foundation and the University of Alberta (PEM), the Canadian Institutes of Health Research (PEM, MOP244739; GSK, MOP119500; MDU, MOP324376) and the Wellcome Trust (MIM, 090532 and 098381; and ALG, 095101). Support for islet isolation and maintenance of the cryogenic bank over the past 20 years has been provided to RVR by the Edmonton Civic Employees Charitable Assistance Fund, the University Hospital Foundation/C.F. 'Curly' and Gladys B. MacLachlan Fund/Paddy and Ken Webb and Family Fund, the Alberta Heritage Foundation for Medical Research and the Alberta Diabetes Foundation.

RCW was supported by summer studentships from Alberta Innovates-Health Solutions and the National Science and Engineering Research Council. AMJS holds a Canada Research Chair in Transplantation Surgery and Regenerative Medicine. MIM is a Wellcome Trust Senior Investigator. ALG is a Wellcome Trust Senior Fellow in Basic Biomedical Science. NMK holds the CHA Chair in Transplantation Research. GLW holds the Charles Nanby Woodward Professorship. PEM holds the Canada Research Chair in Islet Biology.

Duality of interest The authors declare that there is no duality of interest associated with this manuscript.

Contribution statement All authors contributed to the conception and design of the study, data acquisition, analysis and interpretation of the data and manuscript revision, and approved the final version of the paper. JEMF wrote the manuscript. RVR and PEM serve as guarantors of the study design, access to data and the decision to submit and publish the manuscript.

Open Access This article is distributed under the terms of the Creative Commons Attribution 4.0 International License (http:// creativecommons.org/licenses/by/4.0/), which permits unrestricted use, distribution, and reproduction in any medium, provided you give appropriate credit to the original author(s) and the source, provide a link to the Creative Commons license, and indicate if changes were made.

\section{References}

1. Nano R, Bosco D, Kerr-Conte JA et al (2015) Human islet distribution programme for basic research: activity over the last 5 years. Diabetologia 58:1138-1140 
2. Kulkarni RN, Stewart AF (2014) Summary of the keystone islet workshop (April 2014): the increasing demand for human islet availability in diabetes research. Diabetes 63:3979-3981

3. Daoud JT, Petropavlovskaia MS, Patapas JM et al (2011) Longterm in vitro human pancreatic islet culture using threedimensional microfabricated scaffolds. Biomaterials 32:1536-1542

4. Gordon DA, Toledo-Pereyra LH, MacKenzie GH (1982) Preservation for transplantation: a review of techniques of islet cell culture and storage. J Surg Res 32:182-193

5. Schmied BM, Ulrich A, Matsuzaki H et al (2001) Transdifferentiation of human islet cells in a long-term culture. Pancreas 23:157-171

6. Fraga DW, Sabek O, Hathaway DK, Gaber AO (1998) A comparison of media supplement methods for the extended culture of human islet tissue. Transplantation 65:1060-1066

7. Rajotte RV, Stewart HL, Voss WA, Shnitka TK (1977) Viability studies on frozen-thawed rat islets of Langerhans. Cryobiology 14:116-120

8. Ferguson J, Allsopp RH, Taylor RM, Johnston ID (1976) Isolation and preservation of islets from the mouse, rat, guinea-pig and human pancreas. Br J Surg 63:767-773

9. Bretzel RG, Schneider J, Dobroschke J et al (1980) Islet transplantation in experimental diabetes of the rat. VII. Cryopreservation of rat and human islets. Preliminary results. Horm Metab Res 12:274 275

10. Rajotte RV, Warnock GL, McGann LE (1998) Cryopreservation of islets of Langerhans for transplantation. In: Low temperature biotechnology: emerging applications and engineering contributions. McGrath JJ, Diller KR (eds) The American Society of Mechanical Engineers, New York, BED-Vol.10/HTD-Vol.98, pp 25-45

11. Rajotte RV, Warnock GL, Kneteman NM (1992) Methods of islet cryopreservation. In: Pancreatic islet cell transplantation. Ricordi C, ed. R.G. Landes, Austin, Chapter 12, pp 124-131

12. Kneteman NM, Alderson D, Scharp DW, Lacy PE (1989) Longterm cryogenic storage of purified adult human islets of Langerhans. Diabetes 38:386-396

13. Warnock GL, Kneteman NM, Ryan EA et al (1992) Long-term follow-up after transplantation of insulin-producing pancreatic islets into patients with type 1 (insulin-dependent) diabetes mellitus. Diabetologia 35:89-95

14. Lakey JRT, Kin T, Warnock GL et al (2007) Long-term graft function after allogeneic islet transplantation. Cell Transplant 16:441446

15. Li Y, Xue W, Tian X et al (2011) Improved survival and function of rat cryopreserved islets by coculture with Sertoli cells. Artif Organs 35:634-644

16. Omori K, Valiente L, Orr $\mathrm{C}$ et al (2007) Improvement of human islet cryopreservation by a p38 MAPK inhibitor. Am J Transplant 7: $1224-1232$

17. Xue W-J, Luo X-H, Li Y et al (2011) Effects of astragalosides on cultured islets after cryopreservation in rats. Transplant Proc 43: 3908-3912

18. Gatto C, Callegari M, Folin M et al (2003) Effects of cryopreservation and coculture with pancreatic ductal epithelial cells on insulin secretion from human pancreatic islets. Int $\mathrm{J}$ Mol Med 12:851-854

19. Kanitkar M, Bhonde RR (2008) Curcumin treatment enhances islet recovery by induction of heat shock response proteins, Hsp70 and heme oxygenase-1, during cryopreservation. Life Sci 82:182-189

20. Ohnishi K, Murakami M, Morikawa M, Yamaguchi A (2012) Effect of the silk protein sericin on cryopreserved rat islets. J Hepatobiliary Pancreat Sci 19:354-360

21. Matsumoto S, Matsusita M, Morita T et al (2006) Effects of synthetic antifreeze glycoprotein analogue on islet cell survival and function during cryopreservation. Cryobiology 52:90-98
22. Kenmochi T, Asano T, Maruyama M et al (2008) Cryopreservation of human pancreatic islets from non-heart-beating donors using hydroxyethyl starch and dimethyl sulfoxide as cryoprotectants. Cell Transplant 17:61-67

23. Yokogawa Y, Takaki R, Ono J et al (1984) Cryopreservation of pancreatic islet cells. J Lab Clin Med 103:768-775

24. Arata T, Okitsu T, Fukazawa T et al (2004) Maintenance of glucosesensitive insulin secretion of cryopreserved human islets with University of Wisconsin solution and ascorbic acid-2 glucoside. Artif Organs 28:529-536

25. Misler S, Dickey A, Barnett DW (2005) Maintenance of stimulussecretion coupling and single beta-cell function in cryopreservedthawed human islets of Langerhans. Pflugers Arch 450:395-404

26. Warnock GL, Lakey JR, Ao Z, Rajotte RV (1994) Tissue banking of cryopreserved islets for clinical islet transplantation. Transplant Proc 26:3438

27. Warnock GL, Kneteman NM, Ryan E et al (1991) Normoglycaemia after transplantation of freshly isolated and cryopreserved pancreatic islets in type 1 (insulin-dependent) diabetes mellitus. Diabetologia 34:55-58

28. Shapiro AM, Lakey JR, Ryan EA et al (2000) Islet transplantation in seven patients with type 1 diabetes mellitus using a glucocorticoid-free immunosuppressive regimen. N Engl J Med 343:230-238

29. Lamble S, Batty E, Attar M et al (2013) Improved workflows for high throughput library preparation using the transposome-based Nextera system. BMC Biotechnol 13:104

30. Trapnell C, Hendrickson DG, Sauvageau M et al (2013) Differential analysis of gene regulation at transcript resolution with RNA-seq. Nat Biotechnol 31:46-53

31. Manning Fox JE, Seeberger K, Dai XQ et al (2013) Functional plasticity of the human infant $\beta$-cell exocytotic phenotype. Endocrinology 154:1392-1399

32. Loganathan G, Graham ML, Radosevich DM et al (2013) Factors affecting transplant outcomes in diabetic nude mice receiving human, porcine, and nonhuman primate islets: analysis of 335 transplantations. Transplantation 95:1439-1447

33. Cabrera O, Berman DM, Kenyon NS et al (2006) The unique cytoarchitecture of human pancreatic islets has implications for islet cell function. Proc Natl Acad Sci U S A 103:2334-2339

34. Wang RN, Rosenberg L (1999) Maintenance of beta-cell function and survival following islet isolation requires re-establishment of the islet-matrix relationship. J Endocrinol 163:181-190

35. Matsuda T, Suzuki Y, Tanioka Y et al (2003) Pancreas preservation by the 2-layer cold storage method before islet isolation protects isolated islets against apoptosis through the mitochondrial pathway. Surgery 134:437-445

36. Abdelli S, Ansite J, Roduit R et al (2004) Intracellular stress signaling pathways activated during human islet preparation and following acute cytokine exposure. Diabetes 53:2815-2823

37. Thomas D, Yang H, Boffa DJ et al (2002) Proapoptotic Bax is hyperexpressed in isolated human islets compared with antiapoptotic Bcl-2. Transplantation 74:1489-1496

38. Rorsman P, Braun M (2013) Regulation of insulin secretion in human pancreatic islets. Annu Rev Physiol 75:155-179

39. MacDonald PE, Joseph JW, Rorsman P (2005) Glucose-sensing mechanisms in pancreatic beta-cells. Philos Trans R Soc Lond B Biol Sci 360:2211-2225

40. Yan L, Figueroa DJ, Austin CP et al (2004) Expression of voltagegated potassium channels in human and rhesus pancreatic islets. Diabetes 53:597-607

41. Braun M, Ramracheya R, Bengtsson M et al (2008) Voltage-gated ion channels in human pancreatic beta-cells: electrophysiological characterization and role in insulin secretion. Diabetes 57:1618 1628 
42. Kanno T, Ma X, Barg S et al (2004) Large dense-core vesicle exocytosis in pancreatic beta-cells monitored by capacitance measurements. Methods 33:302-311

43. Dai XQ, Plummer G, Casimir M et al (2011) SUMOylation regulates insulin exocytosis downstream of secretory granule docking in rodents and humans. Diabetes 60:838-847
44. Piemonti L, Bertuzzi F, Nano R et al (1999) Effects of cryopreservation on in vitro and in vivo long-term function of human islets. Transplantation 68:655-662

45. Rich SJ, Swift S, Thirdborough SM et al (1994) Islet cryopreservation: a detailed study of total functional losses. Transplant Proc 26: 823-824 